\title{
La dernière lettre
}

John Fletcher

\section{(2) OpenEdition}

Journals

Édition électronique

URL : http://journals.openedition.org/ccs/485

DOI : $10.4000 /$ ccs. 485

ISSN : 2558-782X

\section{Éditeur :}

Presses universitaires de Rennes, Association des lecteurs de Claude Simon

\section{Édition imprimée}

Date de publication : 31 décembre 2006

Pagination : 81-82

ISBN : 9782914518895

ISSN : 1774-9425

\section{Référence électronique}

John Fletcher, "La dernière lettre », Cahiers Claude Simon [En ligne], 2 | 2006, mis en ligne le 20 septembre 2017, consulté le 15 septembre 2020. URL : http://journals.openedition.org/ccs/485 


\section{La dernière lettre}

par John FLETCHER

Dans le département du Nord, près d'Avesnes-sur-Helpe, se trouve un restaurant qui, selon l'expression consacrée, vaut le détour. Il s'agit de l'Auberge Fleurie, à Sars-Poteries. Elle est célèbre bien au-delà des confins de l'arrondissement. Elle est même cotée 8 sur 10 par le très exigeant chroniqueur gastronomique du Times de Londres, Jonathan Meades, qui qualifie son coq à la bière de « révélation".

Le lieu-dit Sars-Poteries dira quelque chose aux simoniens. C'est là, en effet, où en mai 40 le cavalier Simon s'est trouvé dans une embuscade, événement immortalisé dans son chef-d'œuvre La Route des Flandres.

Connaissant bien cette " route des Flandres " qui passe juste devant l'auberge, l'ayant parcourue plus d'une fois pour me mettre "dans la peau » de Claude Simon, je m'y suis attardé un jour de septembre 2004 avec ma femme et cotraductrice Beryl pour goûter aux délices qui avaient tant impressionné M. Meades. Attablés devant la spécialité de l'établissement, nous avons eu l'heureuse idée d'envoyer une carte postale à Claude et Réa pour nous rappeler à leur bon souvenir et pour leur signaler que nous nous trouvions tout près de l'endroit dont s'était inspiré l'un des plus grands romanciers fran- 
çais du vingtième siècle. Cette petite carte postale nous a valu la réponse qui suit. Rédigée d'une main tremblante, ce fut la dernière lettre que nous reçûmes de Claude : elle nous est d'autant plus précieuse.

Paris, le 17 septembre 2004

Chers amis,

Que c'est gentil d'avoir pensé à moi, en passant par Avesnes où j'ai bien failli laisser la vie, il y maintenant plus de soixante ans, un jour de mai, et quel plaisir d'avoir des nouvelles de vous.

Il y a maintenant bien (trop) longtemps que nous ne nous sommes pas vus. Nous espérons que vous vous portez bien - ce qui n'est malheureusement pas mon cas, car j'ai été très malade et ne parviens pas à me rétablir. Je ne sors plus que pour faire à petits pas le tour de la place Monge, et Réa est elle-même très fatiguée. Si vous passez par Paris nous serions très, très heureux de vous voir. Notre téléphone est : [suit le numéro].

On vous embrasse tous deux.

[signé] Claude Réa

Malheureusement nous avions nous-mêmes des problèmes de santé à ce moment-là, et par conséquent nous n'avons pas pu donner suite immédiatement à cette invitation. Lorsque nous nous trouvions en mesure de proposer une date, c'était trop tard. Réa a téléphoné pour dire qu'ils étaient désolés, mais ils étaient trop malades tous les deux pour nous recevoir. Le moment était passé. Quelques mois plus tard, Claude Simon - cet homme qui, connaissant ma date de naissance (1937), m'a dit un jour avec un brin d'humour : "Tenez, vous auriez pu être mon fils ! - n'était plus. 